\title{
Anatomical study of arterial blood supply of the brain in local breed rabbit
}

\author{
A.A. Hasso \\ Department of Anatomy, College of Veterinary Medicine, University of Mosul, Mosul, Iraq
}

\begin{tabular}{l} 
Article information \\
\hline Article history: \\
Received January 27, 2021 \\
Accepted July 11, 2021 \\
Available online November 10, 2021 \\
\hline Keywords: \\
Brain \\
Blood supply \\
Rabbit \\
\\
\hline Correspondence: \\
A.A. Hasso \\
adnanhassoali@gmail.com
\end{tabular}

DOI: $10.33899 /$ ijvs.2021.129231.1636, (CAuthors, 2022, College of Veterinary Medicine, University of Mosul.

This is an open access article under the CC BY 4.0 license (http://creativecommons.org/licenses/by/4.0/).

\section{Introduction}

It is no secret that the brain has great importance in regulating vital processes in the body and the importance of the brain is focused on sustaining life by being appropriate to its surroundings (1). The distribution of arteries in the brain of animals, including mammals, took great interest by those responsible for the studies on the arteries of the brain in various animals, including a description of the blood supply of the giraffe by Frackowiak et al. (2), Felidae by
Frackowiak et al. (3), European beaver by Frackowiak et al. (4), fallow deer by Godynicki (5), deer by Godynicki (6), dog, sheep and other mammals by Kapoor et al. (7), Gerbil by Kuchinka et al. (8), Egyptian mouse by Szczurokowski et al. (9), squirrel by Ayidin (10) and bovine species by Zduin et al. (11). The chinchilla's blood supply was described by (12-14). There are very few studies on brain blood supply in rabbits (15-17). The lack of studies specialized in the brain blood supply of rabbit especially in the local rabbit, in particular, prompted us to 
carry out this study, through which we will highlight the blood supply of the nervous system inside the cranium.

\section{Materials and method}

Fourteen adult healthy rabbits regardless to sex with weight ranging between 3-3.5 kg were taken from the local markets of the city of Mosul. The rabbits were anesthetized by inhalation of chloroform, then an incision was made in the neck area to check the common carotid artery (CCA), to open it and make the animal bleeding, then, $5000 \mathrm{IU}$ of heparin was mixed with normal saline and injected to remove the leftover blood and thrombus present in blood vessels, After that $10 \%$ formalin solution was injected into the blood vessels for fixation and then the CCA was closed by artery forceps and placed in $10 \%$ formalin solution for 72 hours (17).

After that the samples were removed from the formalin solution and washed well with running tap water, then the blood vessels in the other side of the neck were locked to ensure the pass of latex to the head only without spreading to the whole body. After that the samples were injected with the latex substance added to the carmine material, so the carmine works to add color to the latex. The injection was done by the same method of injection of formalin in the body and through the CCA, and then locking the artery with artery forceps and samples were left for 48 hours to solidify the latex. Then the skin and skull bones were removed and the brain, meninges, and part of the spinal cord were harvested (17).

\section{Results}

By following the injected blood vessels, the brain of rabbit was supplied with blood by the vertebral and ICA, the vertebral arteries on both sides connected to form the basal artery that runs along the ventral surface of the pons and medulla oblongata (Figure 1).

On its way, the basal artery send several divisions to end at anterior part near the pons and forming the PCA (Figure 2 and 3), where they originate from the anterior part of the basal artery, as well as, the anterior cerebellar arteries originate from the lateral surface of the basal artery at both sides, it forms an acute angle with the basal artery (Figure 2,3 ), also pons arteries are created, which are small arteries that originated from the lateral surface of the basal artery on both sides, the number ranges from 2-3 arteries on each side (Figure 2 and 3).

Also, the study showed that the 1st posterior cerebellar artery originate from the lateral surface of the basal artery on both sides, and it anastomoses with the 2 nd posterior cerebellar artery that creates a large artery called the posterior cerebellar artery to creates one large posterior cerebellar artery, which branched into several branches that goes to the cerebellum and cerebellar vermis as in (Figure
1-4). We also note the medullary arteries, which are small arteries that originate from the lateral surface of basal artery, and both sides are distributed to ventral surface of medulla oblongata (Figure 1 and 3).

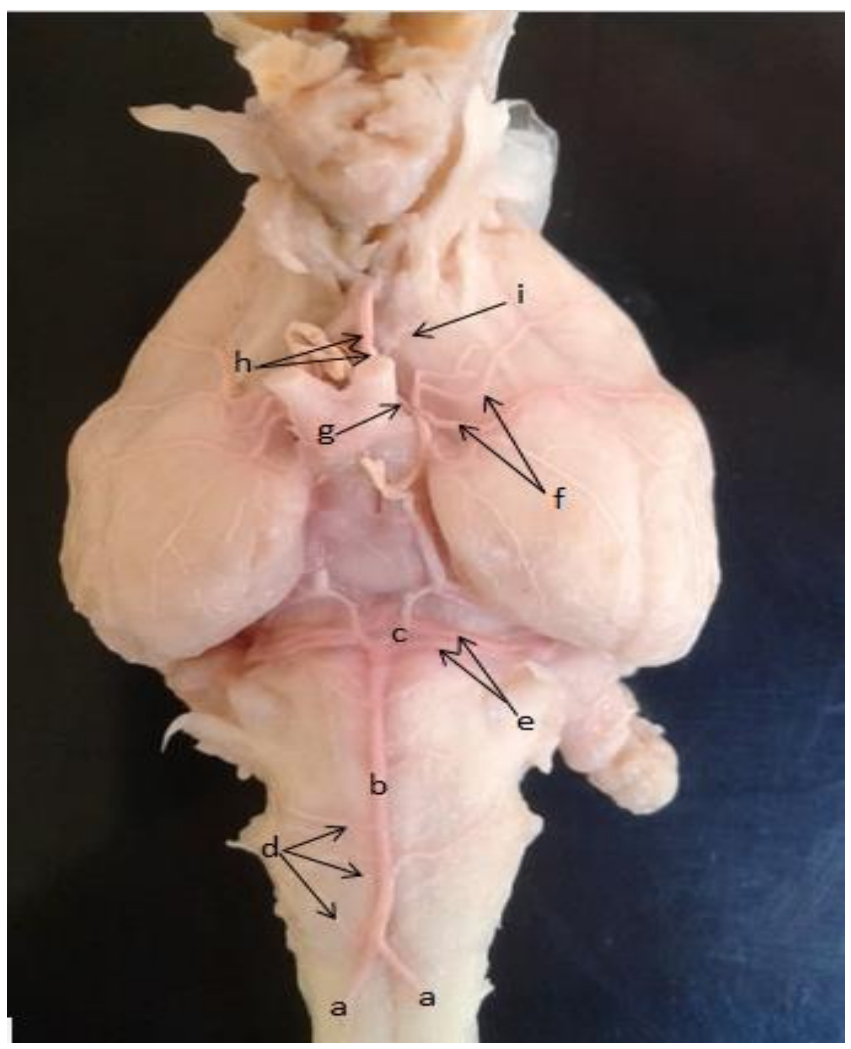

Figure 1: Shows the blood supply and arterial distribution of ventral side of the brain of the local rabbit. a- Vertebral artery b- Basal artery c- Posterior communicating arteries d- medullary arteries e- Posterior cerebellar artery (first and second) f- Middle cerebral artery g- Anterior cerebral artery h- marginal artery i- internal ethmoidal artery.

The ICA is one of the terminal branches of the CCA, It enters the cranium through the foramen lacerum, which branched into several branches and forming the anterior carotid network which is a group of small arteries located at the base of the brain on either side of the pituitary gland in which an anterior artery appears as the intracranial part of the ICA and the posterior artery is the exit from the anterior carotid network and along the ventral side of brain stem which called posterior communicating artery (PCA) (Figure 2-5), also from the intracranial portion of ICA exit artery called accessory anterior communicating artery extends backward to connect with PCA and posterior cerebral artery (Figure 2) forming the closed Willis circle.

The middle cerebral artery (MCA) is created from the intracranial part of the ICA and represents a continuation of the ICA (Figure 1), where it goes forward and laterally to 
be distributed on lateral surfaces of two cerebral hemispheres. Also creates the anterior cerebral artery (ACA) which is one of the terminal part of ICA going forward direction (Figure 1 and 3), Also, we observe the marginal artery, which represents the first terminal part of the ACA that extends forward in front of the medial border of the two cerebral hemispheres (Figure 1 and 3), furthermore, the internal ethmoidal artery is created from the lateral side of the marginal artery which extends after giving internal ethmoidal artery anteriorly and laterally to the olfactory tract and then the olfactory bulb (Figure 1 and $3)$.

The study revealed that the anterior communicating artery arises from the anterior cerebral artery, which is a small artery communicating the right and left ACA (Figure 3 ), whereas the PCA arises from the anterior carotid network (Figure 2 and 3 ) and connect it to the basal artery.

This study appeared that the PCA goes backward on the ventral side of brain stem, where the left and right arteries join to create the anterior part of basal artery (Figure 2).

The PCEA arises from the lateral surface of PCA near its middle (Figure 2 and 3), directed back and laterally on ventral side of brain stem, we also note the anterior cerebellar arteries, which are a group of 4-5 arteries in each side that arise from the PCA and the APCA and the anterior part of basal artery (Figure 3). It is directed laterally on the ventral side of brain stem, then dorsally and inverted, to distribute in the frontal part of the cerebellar and cerebellar vermis.

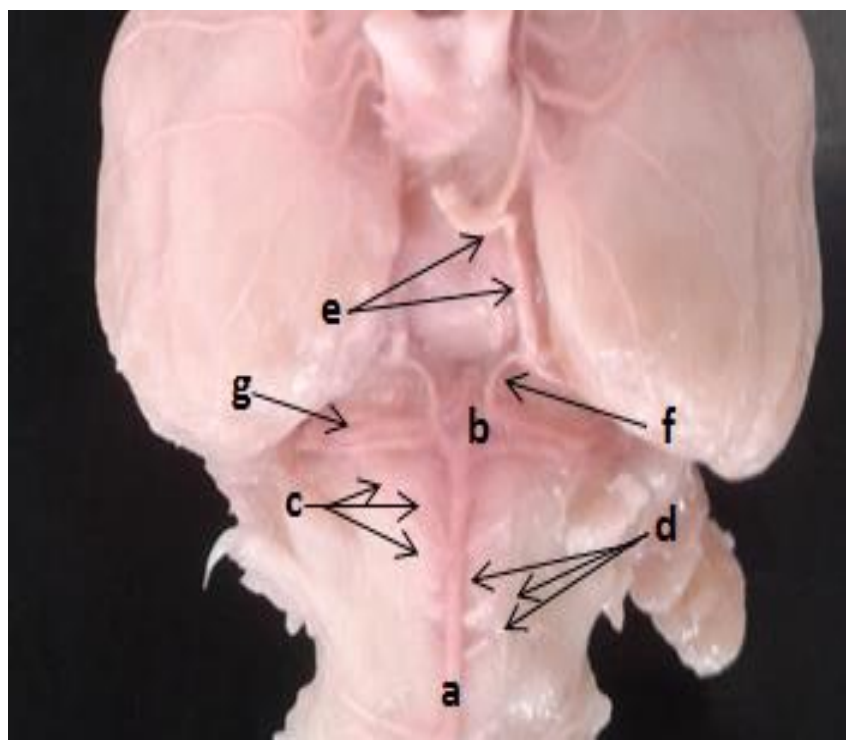

Figure 2: Shows the arterial distribution of the base and pons of the brain and the spinal cord of the local rabbit brain a- Basal artery b- Posterior communicating arteries canterior cerebellar arteries d- pontine arteries e- intracranial part of the internal carotid artery f- accessory anterior communicating artery g- posterior cerebral artery.

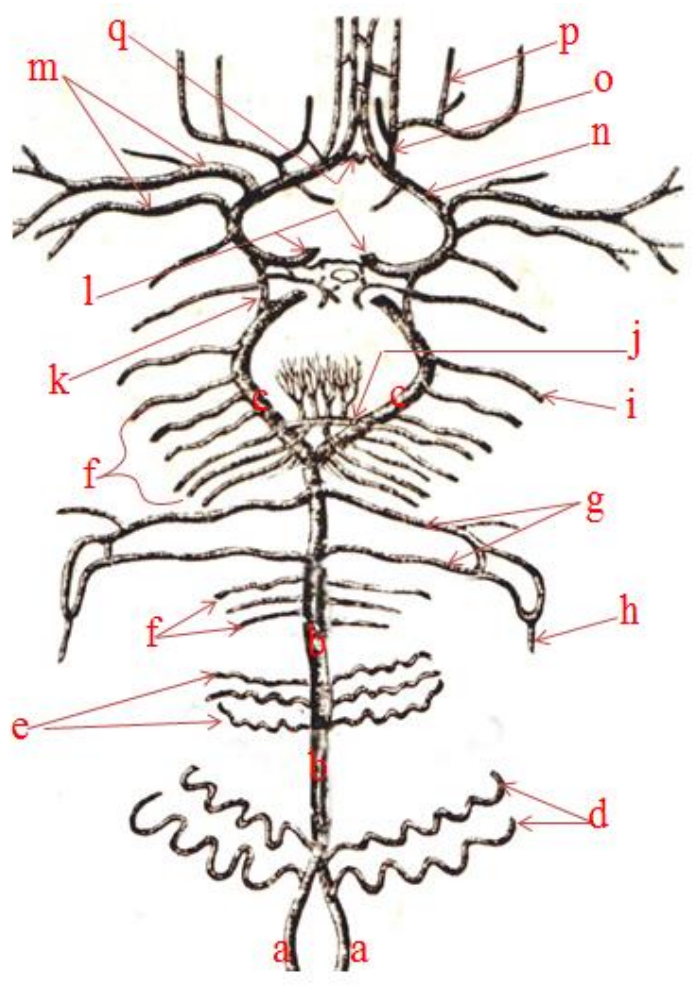

Figure 3: Diagram showing the arterial distribution of the brain in the local rabbit. a- Vertebral artery b- Basal artery c- Posterior communicating arteries d- medullary arteries. e- Pontine arteries f- anterior cerebellar arteries. gPosterior cerebellar artery (first and second). h- Large cerebellar artery i- posterior cerebral artery. j- Accessory posterior communicating artery. k- Accessory anterior communicating artery. I- intracranial part of the internal carotid artery. m- Middle cerebral artery n- Anterior cerebral artery. o- Marginal artery p- internal ethmoidal artery. q- Anterior communicating artery.

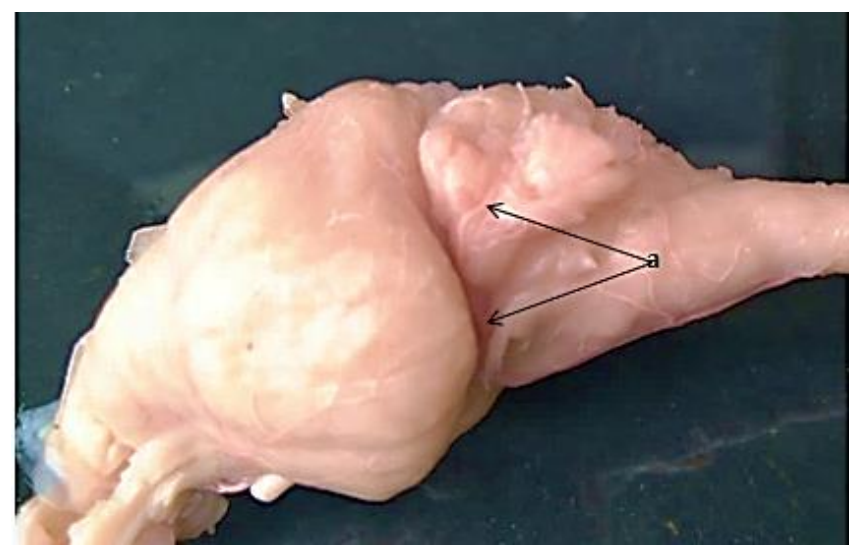

Figure 4: Shows the lateral surface of the rabbit's brain. (a) large posterior cerebellar artery. 


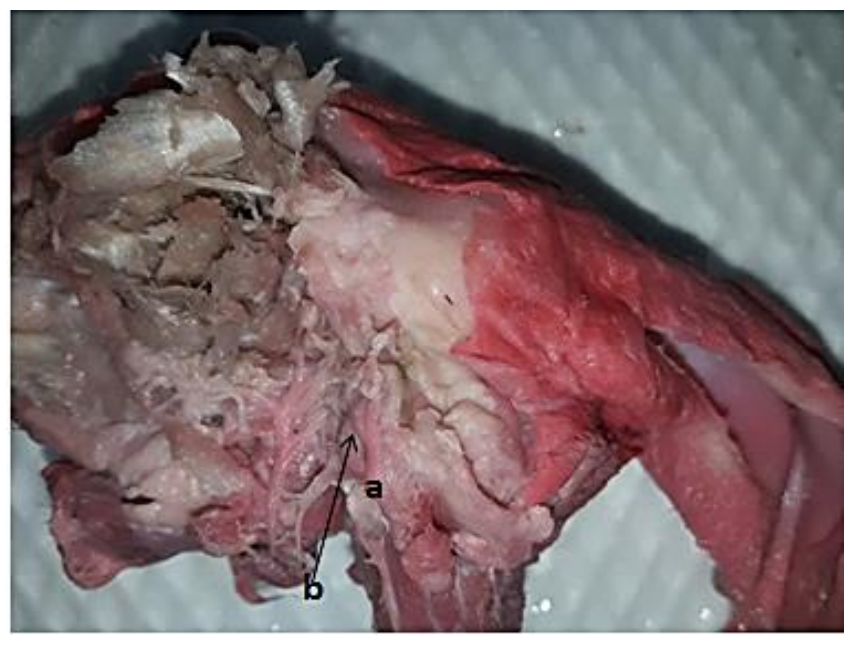

Figure 5: Shows the lateral surface of Rabbit's head after lifting the skin and part of the facial muscles. (a) common carotid artery (b) internal carotid artery.

\section{Discussion}

The blood supply of the brain in rabbits, generally, is similar to most other mammals where the vertebral artery and ICA are considered the chief source of blood supply to the brain. The fused left and right vertebral arteries from the basal artery that supplies the blood to the ventral aspect of brain, similar results were reported by Frackowiak et al. (4) In the European beaver who mentioned that the vertebral arteries on either side fuse to form the basilar artery, which supplies blood to the circulus arteriosus.

Our results approve the findings of Brudnicki et al. (18) in wild rabbits and (17) in New Zealand rabbits who mentioned that the chief source which supply blood to the rabbit brain is the vertebral arteries, which anastomosis to form the basilar artery in addition to the internal carotid arteries. Whereas Aydin et al. (19) mentioned that the ground squirrel's brain is supplied by the left and right vertebral arteries only without referring to the internal carotid artery. This difference in the blood supply of the brain depends on species variations. On its way, the basal artery provides several divisions to end at anterior part near the pons and forming the posterior communicating arteries, where they originate from the anterior part of basal artery. ACA originate from the lateral aspect of the basal artery at both sides, they form an acute angle with the basal artery, also pons arteries which are 2-3 small arteries which originate from the lateral surface of basal artery on both sides. Similar results were recorded by Ayidin et al. (19) in their study on the ground squirrel, who mentioned that the cerebellar and pontine arteries emerged from the basilar artery just before its end.

Also, this study noticed that the 1st PCA originate from the lateral surface of basal artery on both sides, and it anastomoses with the 2 nd posterior cerebellar artery that creates one large posterior cerebellar artery, which gives rise several branches that goes to the cerebellum and cerebellar vermis. Our results confirm the results of Fernanda and Rui (17) who described the basilar artery in New Zealand rabbit where he mentioned that it creates lateral branches at different angles to the right and left, which are two posterior communicating arteries that supply the cerebellum and the cerebellar vermis. The anastomosis of the communicating arteries behind the posterior segment of the ICA creates the posterior cerebellar artery, which continues dorsally to reach the choroid plexus of the fourth ventricle and the caudal lobes of cerebellum. In addition to the above-mentioned branches of the basilar artery, it gives rise to small arteries from its lateral surface called the medullary arteries that distributed on the ventral side of medulla oblongata.

On the other hand, Oscar et al. $(17,20)$ who mentioned that the ICA in New Zealand rabbit is one of the terminal branches of the common carotid artery where enters the cranium through the foramen lacerum, then gives branches that directed forwards and backwards, thus will contributing to form the Willis circle. Actually, the above description of internal carotid artery was similar to our findings in local breed rabbit, additionally, the middle cerebral artery is created from the intracranial part of the internal carotid artery and represents a continuation of the ICA, where goes forward and laterally to be distributed on the lateral side of two cerebral hemispheres. Also, the ACA which created from intracranial ICA going forward direction to give rise the marginal artery, that extends forward in front of the medial border of the two cerebral hemispheres, furthermore, the internal ethmoidal artery is created from the lateral side of marginal artery which extends anteriorly and laterally to the olfactory tract and then to olfactory bulb. These results were described only by $O$ scar et al. (20) in his study on New Zealand rabbit's brain, where he mentioned that the MCA originates from the ICA then directed laterally to feed the two hemispheres of the brain.

The anterior communicating artery, which is a small artery communicating the right and left ACA arises from the anterior cerebral artery whereas the posterior communicating artery originate from the anterior carotid network and connects it to basal artery. This result was similar to that mentioned by Fernanda and Rui (17) in New Zealand rabbit but disagree with Aydin et al. (19) in his study on the ground squirrel, who mentioned that the two ACA join together and form the closed arterial circuit and the absence of the anterior communicating artery in this animal, while he mentioned the presence of the posterior communicating artery that unites with the basilar artery at the ventral surface of the medulla oblongata. This difference may be explained by the absence of the anterior communicating artery in the ground squirrel. 
The posterior cerebral artery originates from the middle of the lateral surface of the PCA artery, directed back and laterally on the ventral side of brain stem while the anterior cerebellar arteries, which are a group of 4-5 arteries on each side that arise from the PCA and the APCA and from anterior part of basal artery. It is directed laterally on the ventral side of brain stem, then dorsally and inverted, to distribute in the frontal part of the cerebellar and cerebellar vermis. This result comes in agreement with Aydin et al. (19) who mentioned that the basilar artery exits from both sides of the cerebellar and pontine arteries before reaching the two posterior communicating arteries at its end, which enter in the formation of the cerebral arterial circuit (Willis circle).

\section{Conclusion}

This study concluded that the intracranial part of the ICA and basilar arteries are the main arteries that supply the brain of rabbits with blood.

\section{Acknowledgments}

This study was supported by the College of Veterinary Medicine, University of Mosul.

\section{Conflict of interest}

The authors declare that there is no conflict of interest regarding publishing or funding of this article.

\section{References}

1. Nathaniel E U. A guide to rabbit production and management. New York: Royal Pace Publications; 2004. 16-22 p.

2. Frackowiak H, Jakubowski $H$. Arterial vascularization in the giraffe brain. Ann Zool Fennici. 2008;45:353-359. DOI: 10.5735 /086.045.0418

3. Frackowiak $\mathrm{H}$, Godynicki S. Brain basal arteries in various species of Felidae. Polish J Vet Sci. 2003;6(3):195-200. [available at]

4. Frackowiak H, Smielowski J. Cephalic arteries in the European beaver (Castor fiber). Act Theriol. 1998;43:219-224. [available at]

5. Godynicki S. Arteries of the head in fallow deer (Dama dama L.). Polskie Archiwum Weterynaryjne. 1972;15:851-864. https://pubmed. [available at]

6. Godynicki S, Wiland C. Cerebral base arteries in the deer. Roczniki Akademii Rolniczej Poznan. 1970;49:45-52. [available at]

7. Kapoor K, Kak VK, Singh B. Morphology and comparative anatomy of circulus arteriosus cerebri in mammals. Ana Histol Embryol. 2003;32:347-355. DOI: 10.1111/j.1439-0264.2003.00492.x

8. Kuchinka J, Nowak E, Szczurkowski A, Kuder T. Arteries supplying the base of the brain in the Mongolian gerbil (Meriones unguiculatus). Pol J Vet Sci. 2008;11(4):295-299. [available at]

9. Szczurkowski A, Kuchinka J, Nowak E, Kuder T. Topography of arterial circle of the brain in Egyptian spiny mouse (Acomys cahirinus, Desmarest). Ana Histol Embryol. 2007;36:147-150. DOI: 10.1111/j.1439-0264.2006.00747.x

10. Aydin A. The morphology of circulus arteriosus cerebri in the red squirrel (Sciurus vulgaris). Vet Med. 2008;53:272-276. DOI: 10.17221/1948-VETMED
11. Zdun M, Frackowiak H, Kieltyka-Kurc A, Kowalczyk K, Nabzdyk M, Timm A. The arteries of brain base in species of bovini tribe. Ana Record. 2013;296:1677-1682. DOI: 10.1002/ar.22784

12. Gielecki JS, Brudnicki W, Nowaki MR. Digital-image analysis of the brain-base arteries in chinchilla, Chinchilla laniger (Molina). Ana Histol Embryol. 1996;25:117-119. DOI: $10.1111 / \mathrm{j} .1439-$ 0264.1996.tb00068.x

13. Jablonski R, Brudnicki W. The effect of blood distribution to the brain on the structure and variability of the cerebral arterial circle in muskrat and in chinchilla. Folia Morpho. 1984;43(2):109-114. [available at]

14. Araujo ACP, Campos R. A systematic study of the brain base arteries and their blood supply sources in the chinchilla (Chinchilla laniger Molina, 1782). Brazilian J Morphol Sci. 2005;22(4):221-232. [available at]

15. Jai S, Lee MD, Mark G, Hamilton MDCM, FRCS(C), Joseph M, Zabramski MD. Variations in the anatomy of the rabbit cervical carotid artery. Stroke. 1994;25(2):501-503. [available at]

16. Matsumoto E, Okumura Y, Miura M. Mechanical and dimensional adaptation of rabbit carotid artery cultured in vitro. Med Biol Eng Comput. 1999;37:252-256. [available at]

17. Fernanda de Souza and Rui Campos. A systematic study of the brain base arteries in the rabbit (Oryctolagus cuniculus). Pesq. Vet Bras. 2013;33(6):796-806. DOI: 10.1590/S0100-736X2013000600018

18. Brudnicki W, Nowicki W, Skoczylas B, Brudnicki A, Stacewicz KK. Arteries of the brain in wild european rabbit Oryctolagus cuniculus (Linnaeus, 1758). Folia Bio. 2012;60(3-4):189-194. DOI: 10.3409/fb60_3-4.189-194

19. Aydin ZE, Ozkan S, Yilmaz R Ilgun. The morphology of the circulus arteriosus cerebri in the ground squirrel (Spermophilus citellus). Vet Med. 2009:54(11):537-542. DOI: 10.17221/162/2009-VETMED

20. Oscar U, Scremin, Ralph R, Sonnenschein and Eduardo $\mathrm{H}$. Rubinstein. Cerebrovascular anatomy and blood flow measurements in the rabbit. J Cereb Blood Flow Metabol. 1982;2(1):55-66. DOI: $\underline{10.1038 / \mathrm{jcbfm} .1982 .6}$
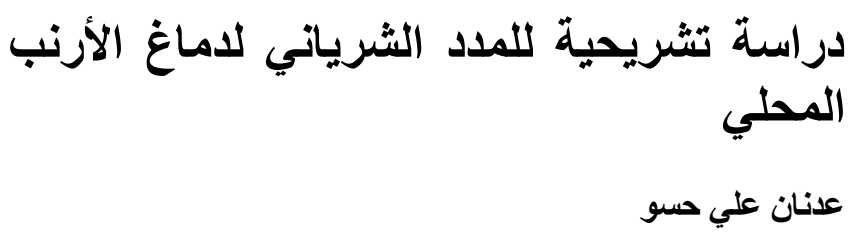

فرع التشريح، كلية الطب البيطري، جامعة الموصل، الموصل، العراق

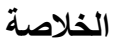

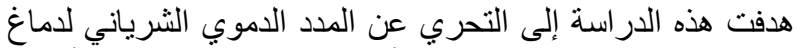

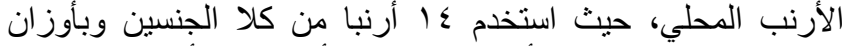

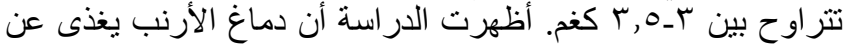

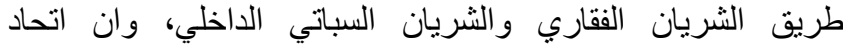
الشريانيين الفقاريين ينتج الشريان القاعدي الذي الثيري يسير على النى السطح

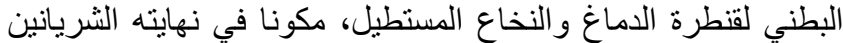

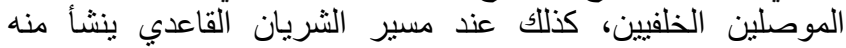
الثرايين الأتية وهي الثرايين المخيخية الامامية والثرايين القنطرية و الثريان المخيخي الخلفي (الأول) و الثريان المخيخي الخلفي (الثاني)

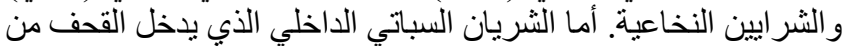

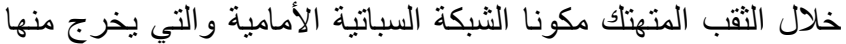

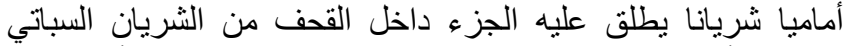

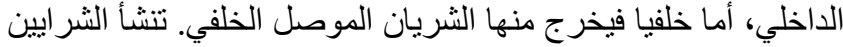
التالية من الجزء داخل القحف للشريان السباتي الداخلي وهي الثــــيان 
الثريان المخي الأمامي وهو شريان صغير يربط الثريانان المخيان

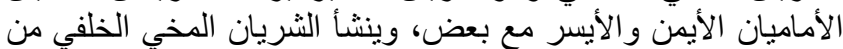

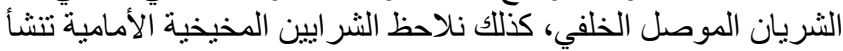

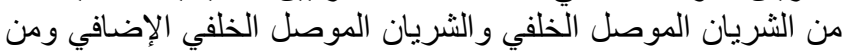
الجزء الأمامي للشريان القاعدي لتغذي نصفي كرة المخيخ الإضيخ والدودة

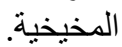

الموصل الأمامي الإضافي الذي يرتبط مع الثريان الموصل الخلفي

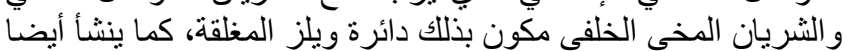

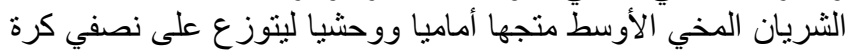

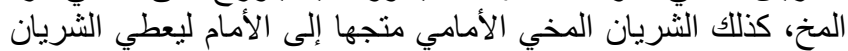

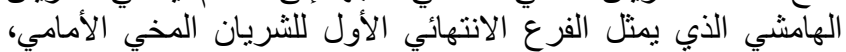

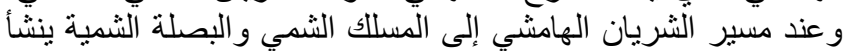

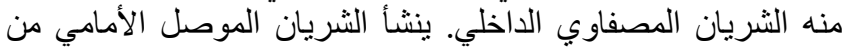

